\title{
An intron polymorphism of the fibronectin gene is associated with end-stage knee osteoarthritis in a Han Chinese population: two independent case-control studies
}

Hsin-Yi Yang ${ }^{1}$, Sui-Lung Su', Yi-Jen Peng ${ }^{2}$, Chih-Chien Wang ${ }^{3,4}$, Herng-Sheng Lee ${ }^{2}$, Donald M Salter ${ }^{5}$ and Chian-Her Lee $6^{6^{*}}$

\begin{abstract}
Background: Knee osteoarthritis $(\mathrm{OA})$ is a complex disease involving both biomechanical and metabolic factors that alter the tissue homeostasis of articular cartilage and subchondral bone. The catabolic activities of extracellular matrix degradation products, especially fibronectin (FN), have been implicated in mediating cartilage degradation. Chondrocytes express several members of the integrin family which can serve as receptors for FN including integrins a5 $\beta 1$, av $\beta 3$, and av $\beta 5$. The purpose of this study was to determine whether polymorphisms in the FN (FN-1) and integrin genes are markers of susceptibility to, or severity of, knee OA in a Han Chinese population.

Methods: Two independent case-control studies were conducted on 928 patients with knee OA and 693 healthy controls. Ten single nucleotide polymorphisms (SNPs) of FN-1 and the integrin aV gene (ITGAV) were detected using the ABI 7500 real-time PCR system.

Results: The AT heterozygote in FN-1 (rs940739A/T) was found to be significantly associated with knee OA (adjusted $\mathrm{OR}=1.44 ; 95 \% \mathrm{Cl}=1.16-1.80$ ) in both stages of the study. FN-1 rs6725958C/A and ITGAV rs10174098A/G SNPs were only associated with knee OA when both study groups were combined. Stratifying the participants by Kellgren-Lawrence (KL) score identified significant differences in the FN-1 rs6725958C/A and rs940739 A/T genotypes between patients with grade $4 \mathrm{OA}$ and controls. Haplotype analyses revealed that TGA and TAA were associated with a higher risk of $O A$, and that TAG conferred a lower risk of knee OA in the combined population.
\end{abstract}

Conclusions: Our study suggests that the FN-1 rs940739A/T polymorphism may be an important risk factor of genetic susceptibility to knee OA in the Han Chinese population.

Keywords: Knee osteoarthritis, Fibronectin gene, Integrin aV gene, Single nucleotide polymorphism

\section{Background}

Osteoarthritis (OA) is a degenerative joint disease that progressively causes loss of joint function and is a leading cause of disability and impaired quality of life among the elderly in developed countries. It is characterized by degeneration and the progressive loss of articular cartilage with pathological changes in bone, synovium, and other soft tissues of affected joints [1]. A number of factors, such

\footnotetext{
* Correspondence: chianherlee@yahoo.com.tw

${ }^{6}$ Department of Orthopedics, School of Medicine, College of Medicine, Taipei Medical University and Hospital, No.250, Wuxing St., Xinyi Dist, Taipei, Taiwan Full list of author information is available at the end of the article
}

as genetic predisposition, aging, obesity, inflammation, and excessive mechanical loading, are recognized to contribute to OA onset and progression [2]. As such, OA is a complex disease involving both biomechanical and metabolic factors that alter the tissue homeostasis of articular cartilage and subchondral bone [3].

The catabolic activities of matrix degradation products, including fibronectin fragments (FN-fs), have been implicated in mediating cartilage degradation $[4,5]$. At least some of these fragments appear to act via an integrin-dependent mechanism [6]. Chondrocytes express

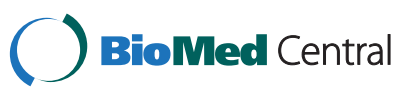

(c) 2014 Yang et al.; licensee BioMed Central Ltd. This is an Open Access article distributed under the terms of the Creative Commons Attribution License (http://creativecommons.org/licenses/by/2.0), which permits unrestricted use, distribution, and reproduction in any medium, provided the original work is properly credited. The Creative Commons Public Domain Dedication waiver (http://creativecommons.org/publicdomain/zero/1.0/) applies to the data made available in this article, unless otherwise stated. 
several members of the integrin family that can serve as FN receptors, including $\alpha 5 \beta 1, \alpha v \beta 3$, and $\alpha v \beta 5[7,8]$.

$\mathrm{FN}$ is encoded by $F \mathrm{~N}-1$, which is located on chromosome $2 \mathrm{q} 34-36$, is over $75 \mathrm{~kb}$ in length and is composed of 50 exons. FN is a multifunctional glycoprotein that is involved in a wide range of biological processes such as cell migration, wound healing, angiogenesis, and differentiation. FN exists in two major forms. The soluble form is found in the plasma, while the insoluble form is present in tissues, including at low levels in the extracellular matrix (ECM) of normal cartilage [9]. Alternative splicing of two type III exons, known as Extra Domains A and B, and a variable region result in the production of up to 20 different FN variants [10]. Growing evidence suggests that these isoforms affect the function of FN and FN-fs, including cartilage breakdown in OA [11].

Integrins are cell surface receptors composed of $\alpha$ and $\beta$ chains. The integrin family consists of at least 24 different heterodimers that are involved in cell-cell and cell-ECM adhesion [12]. Integrin $\alpha \mathrm{V}$ (ITGAV) is one of the more promiscuous alpha integrins associating with five different beta subunits including $\beta 1, \beta 3, \beta 5, \beta 6$, and $\beta 8$ [13]. Expression of ITGAV appears to be upregulated in osteoarthritic chondrocytes [14].

Single nucleotide polymorphisms (SNPs) represent variations in the genome between individuals. Several studies have demonstrated that a number of these polymorphisms are associated with $\mathrm{OA}$ and may contribute to the genetic risk of developing the disease [15-17]. Because $F N-1$ and ITGAV polymorphisms may influence gene expression or modify the biological activities of the functional protein, we set out to test the hypothesis that such polymorphisms influence susceptibility and the severity of knee OA.

\section{Methods}

A total of 928 patients with knee OA and 693 healthy individuals were recruited for two independent studies carried out between July 2008 and December 2009 (the first study conducted in Miaoli, which is located in a largely rural area of China) and between March 2010 and June 2011 (the second study conducted in the centrally located Chinese city of Taipei). The first study recruited and genotyped 403 knee OA patients (65.4\% female) and 314 controls (53.8\% female) to identify knee OA-associated SNPs and haplotypes. The second study recruited and genotyped 525 knee OA patients (65.6\% female) and 379 healthy controls (58.6\% female).

Disease severity in the knee OA populations, who were attending an orthopedic hospital, was assessed by Kellgren-Lawrence $(\mathrm{KL})$ grading. All patients had a KL score $\geq 2$. Other etiologies of knee joint disease such as inflammatory arthritis, post-traumatic or post-septic arthritis, and skeletal or developmental dysplasia were excluded from the study. Healthy control subjects had no signs or symptoms of joint disease (pain, swelling, tenderness, or restriction of movement) and standard $\mathrm{x}$-rays of the knee joints confirmed an absence of OA. This study was reviewed and approved by the institutional ethical committee of Taipei Medical University Hospital and Tri-Service General Hospital (CRC-01-10-03 and TSGH-100-05-023). All clinical and biological samples were collected and DNA was genotyped following approval by this committee. Written informed consent was obtained from all participants after the study had been fully explained to them.

\section{Selection and genotyping of polymorphisms}

We selected $F N-1$ and ITGAV as candidate genes based on the published literature $[18,19]$. SNP genotype information was downloaded from the HapMap database (http:// hapmap.ncbi.nlm.nih.gov/) and The National Center for Biotechnology Information dbSNP database (http://www. ncbi.nlm.nih.gov/snp) to select the most representative SNPs by capturing the majority of genetic variation. Using the tagger program implemented in Haploview 4.0, tag SNPs across $F N-1$ and ITGAV were selected on the basis of linkage disequilibrium patterns observed in the Han Chinese samples genotyped as part of the International HapMap Project. Only SNPs with a minor allele frequency greater than 5\% in HapMap were considered. Six SNPs (rs10202709, rs6725958, rs940739, rs2304573, rs11651, and rs3796123) in FN-1 and four SNPs (rs3911238, rs10174098, rs3738929, and rs1448427) in ITGAV were included to capture as much variation as possible. These 10 tag SNPs captured all alleles with an $\mathrm{r}^{2}$ of at least 0.8 .

Genomic DNA was extracted from the peripheral blood of patients and controls using the QIAamp DNA Blood Mini Kit (QIAGEN Inc., Hilden, Germany) according to the manufacturer's instructions. Genotyping was performed using the TaqMan ${ }^{\circ}$ SNP Genotyping Assay (Applied Biosystems, Foster City, CA, USA) with the following cycling conditions: $95^{\circ} \mathrm{C}$ for $10 \mathrm{~min}$, followed by 40 cycles of $95^{\circ} \mathrm{C}$ for $15 \mathrm{~s}$ and $60^{\circ} \mathrm{C}$ for $1 \mathrm{~min}$, with a $1 \mathrm{~min}$ extension at $25^{\circ} \mathrm{C}$ following the last cycle. Genotyping was performed by laboratory personnel blinded to case status and $10 \%$ of the samples were randomly selected for repeated testing to validate genotyping procedures. Two authors independently reviewed the genotyping results, data entry, and statistical analyses.

\section{Statistical analysis}

Statistical analysis was performed using SPSS for Windows version 18.0 software (SPSS, Chicago, IL, USA), and results were considered statistically significant where the two-tailed $p$-value was less than 0.05. SNP deviations from the Hardy-Weinberg equilibrium (HWE) in control samples were assessed using the standard chi-squared $\left(\mathrm{X}^{2}\right)$ 
test. The allele and genotype frequencies of OA patients and control subjects were compared using $X^{2}$ statistics or Fisher's exact test as appropriate. The demographics were evaluated by the Student's $t$-test or Mann-Whitney U test for continuous variables and expressed as means \pm standard deviation (SD). Logistic regression was used to estimate crude and adjusted age, gender, and body mass index (BMI) odd ratios (ORs) and 95\% confidence intervals (CIs) as a measure of association with the risk of OA.

Linkage disequilibrium and haplotype analyses were performed using Haploview software (http://www.broad. mit.edu/mpg/haploview/) [20]. Because the frequency distributions of demographic characteristics and genotypic and allelic distributions of the 10 SNPs were similar between the two study cohorts, all data were pooled to analyze the association between SNPs and knee OA. In the absence of interstudy heterogeneity within samples, we also constructed a Mantel-Haenszel meta-analysis of sample data to assess the overall evidence of association. The Mantel-Haenszel $\chi^{2}$ test and estimate of the OR were computed with or without the inclusion of covariates using R, version 3.0.2, with the "metafor" and "meta" packages.

The assumption of heterogeneity for each analysis was tested using the DerSimonian-Laird method. The level of significance was determined by Bonferroni's method for correcting multiple testing errors. For the 10 selected SNPs, a $p$-value $<0.005(0.05$ divided by 10$)$ was considered statistically significant. In this study, power estimation was performed using CaTS (http://www. sph.umich.edu/csg/abecasis/CaTS/) and is summarized in Additional file 1: Table S1.

\section{Results}

\section{Characteristics of study subjects}

The frequency distributions of demographic characteristics between the 928 knee OA cases and 693 healthy controls in the two independent studies are shown in Table 1. The average age of knee OA cases was significantly higher than the control population. The proportion of females in the knee OA cases (65.5\%) was significantly higher than in the healthy controls (56.4\%). BMI was also slightly higher in the knee OA cases.

\section{Association analyses of $\mathrm{FN}-1$ polymorphisms with susceptibility to $O A$}

Table 2 shows the genotype distributions and allele frequencies of $F N-1$ polymorphisms in knee OA and control subjects from both studies. The genotype frequencies of all six $F N-1$ SNPs were in HWE $(p>0.05)$. In study 1 , the genotype distribution of $F N-1$ rs $940739 \mathrm{~A} / \mathrm{T}$ was significantly different between knee OA patients and healthy controls $(p<0.05)$. When the $F N-1$ rs940739AA genotype was used as the reference group, the rs940739AT genotype appeared to be associated with a higher risk for knee OA (adjusted OR $=1.44,95 \% \mathrm{CI}=1.03-2.01$ ). To determine whether the results could be replicated, we genotyped the six SNPs in the second study population. In this study group, rs940739AT also differed significantly in genotype distribution between the knee $\mathrm{OA}$ cases and healthy controls (adjusted $\mathrm{OR}=1.48,95 \% \mathrm{CI}=1.10-1.99$ ).

The other FN-1 SNPs (rs10202709G/A, rs6725958C/A, rs2304573G/A, rs11651A/G, and rs3796123T/A) demonstrated no significant genotypic or allelic association between OA cases and healthy controls in either of the two study groups (Table 2).

\section{Association analyses for $\mathrm{FN}-1$ polymorphisms in the combined studies}

When data from the two independent studies were combined, the association of the rs940739A/T polymorphism with knee OA was maintained (adjusted $\mathrm{OR}=1.44$, 95\% $\mathrm{CI}=1.16-1.80, p=0.001$ ). Additionally, the minor allele of $F N-1$ rs6725958C/A appeared to be associated with a significantly higher risk of knee OA (adjusted $\mathrm{OR}=1.17$, 95\% $\mathrm{CI}=1.01-1.80, p=0.033$ ) (Table 3 ). After correcting

Table 1 Characteristics of OA cases and healthy controls

\begin{tabular}{|c|c|c|c|c|c|c|c|}
\hline \multirow[t]{2}{*}{ Variables } & \multicolumn{2}{|l|}{ Study 1} & \multicolumn{2}{|l|}{ Study 2} & \multicolumn{2}{|c|}{ Study 1 + Study 2} & \multirow[b]{2}{*}{$p$} \\
\hline & Case (\%) & Control (\%) & Case (\%) & Control (\%) & Case (\%) & Control (\%) & \\
\hline Number & 403 & 314 & 525 & 379 & 928 & 693 & \\
\hline Age (mean $\pm S D)$ & $72.54 \pm 8.13$ & $69.34 \pm 9.80$ & $72.18 \pm 8.12$ & $69.87 \pm 9.96$ & $72.34 \pm 8.13$ & $69.63 \pm 9.88$ & $<0.001$ \\
\hline Gender (\% Female) & $65.4 \%$ & $53.8 \%$ & $65.6 \%$ & $58.6 \%$ & $65.5 \%$ & $56.4 \%$ & $<0.001$ \\
\hline $\mathrm{BMI}($ mean $\pm \mathrm{SD})$ & $25.28 \pm 3.13$ & $24.95 \pm 9.88$ & $25.08 \pm 3.16$ & $24.26 \pm 3.79$ & $25.17 \pm 3.15$ & $24.57 \pm 7.22$ & 0.04 \\
\hline \multicolumn{8}{|l|}{ K-L grading (\%) } \\
\hline Grade 0 & 0 & $162(51.60)$ & 0 & $189(49.87)$ & 0 & 351 (50.65) & \\
\hline Grade 1 & 0 & $152(48.40)$ & 0 & $190(50.13)$ & 0 & $342(49.35)$ & \\
\hline Grade 2 & $146(36.23)$ & 0 & 205 (39.05) & 0 & 351 (37.82) & 0 & \\
\hline Grade 3 & $73(18.11)$ & 0 & $74(14.10)$ & 0 & $147(15.84)$ & 0 & \\
\hline Grade 4 & $184(45.66)$ & 0 & $246(46.85)$ & 0 & $430(46.34)$ & 0 & \\
\hline
\end{tabular}


Table 2 Genotype distributions of FN-1 polymorphisms and their association with $\mathrm{OA}$ risk

\begin{tabular}{|c|c|c|c|c|c|c|c|}
\hline \multirow[t]{2}{*}{ SNP } & & \multicolumn{2}{|c|}{ Study 1} & \multirow[b]{2}{*}{ Adjusted OR $(95 \% \mathrm{Cl}){ }^{\#}$} & \multicolumn{2}{|c|}{ Study 2} & \multirow[b]{2}{*}{ Adjusted OR $(95 \% \mathrm{Cl})$} \\
\hline & & Case & Control & & Case & Control & \\
\hline \multirow[t]{5}{*}{ rs10202709 } & GG & 376 & 300 & 1 & 488 & 351 & 1 \\
\hline & GA & 26 & 13 & $1.64(0.81-3.33)$ & 35 & 27 & $0.88(0.52-1.52)$ \\
\hline & AA & 1 & 1 & $1.00(0.06-16.72)$ & 2 & 1 & $1.24(0.11-14.25)$ \\
\hline & G & 0.96 & 0.98 & 1 & 0.96 & 0.96 & 1 \\
\hline & A & 0.04 & 0.02 & $1.54(0.80-2.97)$ & 0.04 & 0.04 & $0.94(0.55-1.52)$ \\
\hline \multirow[t]{5}{*}{ rs6725958 } & CC & 113 & 102 & 1 & 120 & 111 & 1 \\
\hline & CA & 200 & 158 & $1.08(0.76-1.54)$ & 289 & 197 & $1.25(0.90-1.72)$ \\
\hline & AA & 90 & 54 & $1.44(0.92-2.25)$ & 116 & 71 & $1.37(0.92-2.05)$ \\
\hline & C & 0.53 & 0.58 & 1 & 0.50 & 0.55 & 1 \\
\hline & A & 0.47 & 0.42 & $1.18(0.95-1.47)$ & 0.50 & 0.45 & $1.16(0.96-1.41)$ \\
\hline \multirow[t]{5}{*}{ rs940739 } & AA & 240 & 208 & 1 & 310 & 260 & 1 \\
\hline & AT & 146 & 94 & $1.44(1.03-2.01)^{*}$ & 191 & 104 & $1.48(1.10-1.99)^{*}$ \\
\hline & $\pi$ & 17 & 12 & $1.07(0.49-2.36)$ & 24 & 15 & $1.15(0.58-2.28)$ \\
\hline & A & 0.78 & 0.81 & 1 & 0.77 & 0.82 & 1 \\
\hline & T & 0.22 & 0.19 & $1.26(0.96-1.65)$ & 0.23 & 0.18 & $1.30(1.02-1.65)^{*}$ \\
\hline \multirow[t]{5}{*}{ rs2304573 } & GG & 227 & 173 & 1 & 302 & 212 & 1 \\
\hline & GA & 146 & 119 & $0.95(0.68-1.31)$ & 189 & 137 & $0.99(0.74-1.33)$ \\
\hline & AA & 30 & 22 & $1.15(0.63-2.10)$ & 34 & 30 & $0.80(0.47-1.36)$ \\
\hline & G & 0.74 & 0.74 & 1 & 0.75 & 0.74 & 1 \\
\hline & A & 0.26 & 0.26 & $1.02(0.79-1.30)$ & 0.25 & 0.26 & $0.93(0.75-1.17)$ \\
\hline \multirow[t]{5}{*}{ rs11651 } & $\mathrm{AA}$ & 190 & 138 & 1 & 251 & 167 & 1 \\
\hline & $A G$ & 170 & 130 & $0.93(0.67-1.29)$ & 213 & 164 & $0.89(0.66-1.19)$ \\
\hline & GG & 43 & 46 & $0.71(0.44-1.16)$ & 61 & 48 & $0.85(0.55-1.31)$ \\
\hline & A & 0.68 & 0.65 & 1 & 0.68 & 0.66 & 1 \\
\hline & G & 0.32 & 0.35 & $0.86(0.68-1.08)$ & 0.32 & 0.34 & $0.91(0.74-1.11)$ \\
\hline \multirow[t]{5}{*}{ rs3796123 } & $\pi$ & 338 & 259 & 1 & 430 & 318 & 1 \\
\hline & TA & 61 & 52 & $0.83(0.54-1.27)$ & 87 & 60 & $1.07(0.74-1.54)$ \\
\hline & $\mathrm{AA}$ & 4 & 3 & $1.02(0.22-4.68)$ & 8 & 1 & $6.17(0.73-52.51)$ \\
\hline & T & 0.91 & 0.91 & 1 & 0.90 & 0.92 & 1 \\
\hline & A & 0.09 & 0.09 & $0.87(0.59-1.27)$ & 0.10 & 0.08 & $1.21(0.86-1.70)$ \\
\hline
\end{tabular}

${ }^{*} p<0.05$; "Data have been adjusted by gender, age and BMI.

for multiple comparisons, the $F N-1$ rs940739TA genotype had a higher risk for OA, but the minor allele of $F N-1$ rs6725958C/A was not significant.

\section{Association analyses for ITGAV polymorphisms in the combined studies}

Genotypic and allelic distributions of the four ITGAV SNPs and their associations with knee OA risk are shown in Table 4. No deviation from the HWE was observed in the controls $(p>0.05)$. There was no significant genotypic or allelic association identified between the knee OA cases and healthy controls with the four ITGAV SNPs in both study cohorts. However, when data from the two independent studies were combined,
rs10174098A/G was associated with a lower risk of knee OA (adjusted OR $=0.77,95 \% \mathrm{CI}=0.62-0.96, p=0.020$ ).

In males, significant associations were observed between ITGAV rs3738919C/A and OA (Additional file 1: Table S4), but no associations were found between $\mathrm{OA}$ and $F N-1$ polymorphisms among males (Additional file 1: Table S2). In females, genotypic and allelic frequencies of $F N-1$ rs6725958C/A and rs940739A/T and ITGAV rs10174098A/ G polymorphisms differed significantly between knee OA cases and healthy controls (Additional file 1: Tables S3 and S4). Additionally, the dominant mode of $F N-1$ rs640739 also appeared to be associated with a significantly higher risk of knee OA (adjusted OR $=1.41,95 \%$ $\mathrm{CI}=1.14-1.74, p=0.002$ ) (Additional file 1: Table S5). 
Table 3 Association analyses for FN-1 SNPs with OA in the combined analyses of both study groups

\begin{tabular}{|c|c|c|c|c|c|c|c|}
\hline SNP & & Case & Control & Simply pooled OR $(95 \% \mathrm{Cl})^{\#}$ & $p$ & $\mathrm{OR}_{\text {Meta }}(95 \% \mathrm{Cl})^{\#}$ & $1^{2}$ \\
\hline \multirow[t]{5}{*}{ rs10202709 } & GG & 864 & 651 & 1 & & 1 & \\
\hline & GA & 61 & 40 & $1.13(0.74-1.72)$ & 0.583 & $1.15(0.63-2.10)$ & 47.99 \\
\hline & AA & 3 & 2 & $1.15(0.19-711)$ & 0.881 & $1.13(0.18-7.09)$ & 0 \\
\hline & G & 0.96 & 0.97 & 1 & & 1 & \\
\hline & A & 0.04 & 0.03 & $1.24(0.76-1.67)$ & 0.565 & $1.16(0.72-1.87)$ & 23.50 \\
\hline \multirow[t]{5}{*}{ rs6725958 } & $C C$ & 233 & 213 & 1 & & 1 & \\
\hline & $C A$ & 489 & 355 & $1.17(0.92-1.48)$ & 0.201 & $1.08(0.76-1.53)$ & 0 \\
\hline & AA & 206 & 125 & $1.39(1.03-1.88)$ & 0.030 & $1.40(1.04-1.89)$ & 0 \\
\hline & C & 0.52 & 0.56 & 1 & & 1 & \\
\hline & A & 0.48 & 0.44 & $1.17(1.01-1.35)$ & 0.033 & $1.17(1.01-1.35)$ & 0 \\
\hline \multirow[t]{5}{*}{ rs940739 } & AA & 550 & 468 & 1 & & 1 & \\
\hline & AT & 337 & 198 & $1.44(1.16-1.80)$ & $0.001 \&$ & $1.46(1.17-1.83)$ & 0 \\
\hline & $\pi$ & 41 & 27 & $1.14(0.68-1.91)$ & 0.624 & $1.11(0.67-1.86)$ & 0 \\
\hline & A & 0.77 & 0.82 & 1 & & 1 & \\
\hline & $\mathrm{T}$ & 0.23 & 0.18 & $1.28(1.07-1.53)$ & 0.008 & $1.28(1.07-1.54)$ & 0 \\
\hline \multirow[t]{5}{*}{ rs2304573 } & GG & 529 & 385 & 1 & & 1 & \\
\hline & GA & 335 & 256 & $0.97(0.78-1.20)$ & 0.754 & $0.97(0.78-1.21)$ & 0 \\
\hline & $\mathrm{AA}$ & 64 & 52 & $0.93(0.62-1.38)$ & 0.701 & $0.94(0.63-1.40)$ & 0 \\
\hline & G & 0.75 & 0.74 & 1 & & 1 & \\
\hline & A & 0.25 & 0.26 & $0.96(0.82-1.13)$ & 0.647 & $0.97(0.82-1.14)$ & 0 \\
\hline \multirow[t]{5}{*}{ rs11651 } & $\mathrm{AA}$ & 441 & 305 & 1 & & 1 & \\
\hline & $A G$ & 383 & 294 & $0.90(0.73-1.12)$ & 0.359 & $0.91(0.73-1.13)$ & 0 \\
\hline & GG & 104 & 94 & $0.78(0.57-1.08)$ & 0.138 & $0.78(0.57-1.08)$ & 0 \\
\hline & A & 0.68 & 0.65 & 1 & & 1 & \\
\hline & G & 0.32 & 0.35 & $0.88(0.76-1.03)$ & 0.112 & $0.89(0.76-1.04)$ & 0 \\
\hline \multirow[t]{5}{*}{ rs3796123 } & $\pi$ & 768 & 577 & 1 & & 1 & \\
\hline & TA & 148 & 112 & $0.95(0.72-1.25)$ & 0.691 & $0.96(0.73-1.27)$ & 0 \\
\hline & AA & 12 & 4 & $2.14(0.67-6.87)$ & 0.202 & $2.14(0.38-12.14)$ & 44.49 \\
\hline & $\mathrm{T}$ & 0.91 & 0.91 & 1 & & 1 & \\
\hline & A & 0.09 & 0.09 & $1.03(0.80-1.33)$ & 0.818 & $1.04(0.75-1.44)$ & 36.03 \\
\hline
\end{tabular}

"Data have been adjusted by gender, age and BMl; \&p-values were based upon Bonferroni's method.

In the recessive mode, the $10 F N-1$ and ITGAV SNPs showed no significance (Additional file 1: Table S6). After correcting for multiple comparisons, no SNPs appeared to be associated with OA. We further analyzed interactions between $F N-1$ rs940739A/T and obesity, but observed no significant interaction between the two $(p$ for interaction $=$ 0.15 for the interaction term, Additional file 1: Table S7).

\section{Stratification analysis according to disease severity}

Stratifying the patients by KL score identified significant differences in $F N-1$ rs6725958C/A alleles and genotypes between patients with both grade 3 and 4 knee OA and controls (AA/CC, adjusted $\mathrm{OR}=2.11,95 \% \mathrm{CI}=1.45-3.06$; adjusted $\mathrm{OR}=0.54,95 \% \mathrm{CI}=0.36-0.82$; $\mathrm{CA} / \mathrm{CC}$, adjusted $\mathrm{OR}=1.58,95 \% \mathrm{CI}=1.16-2.16) . F N-1 \mathrm{rs} 940739 \mathrm{~A} / \mathrm{T}$ was also associated with grade 4 knee OA (AT/AA, adjusted $\mathrm{OR}=2.07,95 \% \mathrm{CI}=1.59-2.69)($ Table 5$)$.

\section{Haplotype analysis of $\mathrm{FN}-1$}

Linkage disequilibrium analysis confirmed disequilibrium between SNPs rs2304573 and rs11651 $\left(r^{2}=0.73\right.$; data not shown). The haplotype analysis of $F N-1$ polymorphisms in knee OA cases and control subjects is shown in Table 6. The frequency of haplotype AAG was $6.6 \%$ in knee OA patients compared with $10.1 \%$ in controls $(\mathrm{OR}=0.63$, 95\% $\mathrm{CI}=0.49-0.81, p<0.001)$. By contrast, haplotypes TGA and TAA were more common in knee OA patients (4.7\% and $2.2 \%$, respectively) than controls $(2.4 \%$ and $1.0 \%$, respectively) $(\mathrm{OR}=2.03$ and $2.12,95 \% \mathrm{CI}=1.35-3.06$ and $1.16-3.89, p<0.001$ and $=0.013$, respectively). 
Table 4 Genotype distributions of ITGAV polymorphisms and their association with OA risk

\begin{tabular}{|c|c|c|c|c|c|c|c|c|c|c|}
\hline \multirow[t]{2}{*}{ SNP } & & \multicolumn{2}{|c|}{ Study 1} & \multirow[b]{2}{*}{ OR $(95 \% \mathrm{Cl})^{\#}$} & \multicolumn{2}{|c|}{ Study 2} & \multirow[b]{2}{*}{ OR $(95 \% \mathrm{Cl})^{\#}$} & \multicolumn{2}{|c|}{ Study $1+$ Study 2} & \multirow[b]{2}{*}{$1^{2}$} \\
\hline & & Case & Control & & Case & Control & & OR $(95 \% \mathrm{CI})^{\# \$}$ & $\mathrm{OR}_{\text {Meta }}$ & \\
\hline \multirow[t]{5}{*}{ rs3911238 } & GG & 294 & 216 & 1 & 381 & 266 & 1 & 1 & 1 & \\
\hline & GC & 99 & 89 & $0.84(0.59-1.82)$ & 129 & 101 & $0.86(0.63-1.18)$ & $0.84(0.67-1.06)$ & $0.85(0.67-1.08)$ & 0 \\
\hline & $\mathrm{CC}$ & 10 & 9 & $0.92(0.36-2.40)$ & 15 & 12 & $0.92(0.42-2.03)$ & $0.93(0.51-1.72)$ & $0.92(0.50-1.68)$ & 0 \\
\hline & G & 0.85 & 0.83 & 1 & 0.85 & 0.84 & 1 & 1 & 1 & \\
\hline & C & 0.15 & 0.17 & $0.87(0.65-1.17)$ & 0.15 & 0.16 & $0.89(0.69-1.16)$ & $0.88(0.73-1.07)$ & $0.88(0.73-1.07)$ & 0 \\
\hline \multirow[t]{5}{*}{ rs10174098 } & $\mathrm{AA}$ & 285 & 209 & 1 & 351 & 240 & 1 & 1 & 1 & \\
\hline & $A G$ & 104 & 96 & $0.74(0.52-1.04)$ & 154 & 129 & $0.77(0.57-1.03)$ & $0.77(0.62-0.96)$ & $0.76(0.60-0.95)$ & 0 \\
\hline & GG & 14 & 9 & $1.27(0.53-3.05)$ & 20 & 10 & $1.19(0.53-2.64)$ & $1.22(0.68-2.20)$ & $1.23(0.68-2.22)$ & 0 \\
\hline & A & 0.84 & 0.82 & 1 & 0.82 & 0.80 & 1 & 1 & 1 & \\
\hline & G & 0.16 & 0.18 & $0.86(0.65-1.14)$ & 0.18 & 0.20 & $0.87(0.68-1.11)$ & $0.88(0.73-1.05)$ & $0.87(0.72-1.04)$ & 0 \\
\hline \multirow[t]{5}{*}{ rs3738919 } & CC & 366 & 273 & 1 & 468 & 344 & 1 & 1 & 1 & \\
\hline & CA & 35 & 37 & $0.66(0.39-1.09)$ & 54 & 44 & $0.87(0.56-1.34)$ & $0.77(0.55-1.06)$ & $0.78(0.55-1.09)$ & 0 \\
\hline & $\mathrm{AA}$ & 2 & 4 & $0.29(0.05-1.70)$ & 3 & 1 & $2.18(0.22-21.58)$ & $0.70(0.19-2.50)$ & $0.69(0.10-4.90)$ & 46.58 \\
\hline & C & 0.95 & 0.93 & 1 & 0.94 & 0.94 & 1 & 1 & 1 & \\
\hline & A & 0.05 & 0.07 & $0.60(0.38-0.95)$ & 0.06 & 0.06 & $0.93(0.62-1.40)$ & $0.77(0.57-1.04)$ & $0.76(0.49-1.16)$ & 49.44 \\
\hline \multirow[t]{5}{*}{ rs1448427 } & $\mathrm{AA}$ & 267 & 196 & 1 & 325 & 234 & 1 & 1 & 1 & \\
\hline & $A G$ & 123 & 108 & $0.90(0.37-2.18)$ & 179 & 129 & $1.00(0.49-2.03)$ & $0.91(0.74-1.13)$ & $0.96(0.55-1.67)$ & 0 \\
\hline & GG & 13 & 10 & $0.79(0.57-1.10)$ & 21 & 16 & $1.00(0.75-1.34)$ & $0.96(0.55-1.66)$ & $0.90(0.72-1.13)$ & 11.32 \\
\hline & A & 0.82 & 0.80 & 1 & 0.79 & 0.79 & 1 & 1 & 1 & \\
\hline & G & 0.18 & 0.20 & $0.85(0.65-1.12)$ & 0.21 & 0.21 & $1.00(0.79-1.27)$ & $0.94(0.79-1.12)$ & $0.93(0.78-1.11)$ & 0 \\
\hline
\end{tabular}

"Data have been adjusted by gender, age and BMI; ${ }^{5}$ Simply pooled OR.

Table 5 Association of $F N-1$ rs6725958 and rs940739 polymorphisms among different grade $O A$ cases and controls

\begin{tabular}{lll}
\hline $\begin{array}{l}\text { Genetic risk Genotype Cases Model } \\
\text { factor }\end{array}$ & \begin{tabular}{l}
$\mathrm{K} / \mathrm{L}$ score \\
\cline { 2 - 3 }
\end{tabular} \\
\hline
\end{tabular}

rs6725958

\begin{tabular}{|c|c|c|c|c|}
\hline 233 & $\mathrm{AA} / \mathrm{CC}$ & 2 & $1.10(0.74-1.65)$ & 0.628 \\
\hline 489 & $\mathrm{AA} / \mathrm{CC}$ & 3 & $0.81(0.49-1.35)$ & 0.418 \\
\hline \multirow[t]{4}{*}{$\mathrm{AA}$} & $\mathrm{AA} / \mathrm{CC}$ & 4 & $2.11(1.45-3.06)$ & $<0.001$ \\
\hline & $\mathrm{CA} / \mathrm{CC}$ & 2 & $1.14(0.83-1.55)$ & 0.427 \\
\hline & $\mathrm{CA} / \mathrm{CC}$ & 3 & $0.54(0.36-0.82)$ & 0.003 \\
\hline & CA/CC & 4 & $1.58(1.16-2.16)$ & 0.004 \\
\hline
\end{tabular}

rs940739

$\begin{array}{llllll}\text { AA } & 550 & \text { TT/AA } & 2 & 1.12(0.59-2.14) & 0.729 \\ \text { AT } & 337 & \text { TT/AA } & 3 & 1.37(0.59-3.18) & 0.465 \\ \Pi 1 & 41 & \text { TT/AA } & 4 & 1.15(0.59-2.24) & 0.668 \\ & & \text { TA/AA } & 2 & 0.96(0.71-1.30) & 0.801 \\ & & \text { TA/AA } & 3 & 1.22(0.82-1.18) & 0.339 \\ & & \text { TA/AA } & 4 & 2.07(1.59-2.69) & <0.001\end{array}$

${ }^{\$}$ Grade 0,1 as a reference category; OA cases $=$ study $1+$ study $2 ;{ }^{*}$ Data have been adjusted by gender, age and BMI.

\section{Discussion}

After conducting two independent studies involving the genotyping and evaluation of disease severity of 928 knee OA patients and 693 healthy controls from a Han Chinese population, we have identified an association between the FN-1 rs940739A/T SNP and OA. When data from both studies were combined, we also identified an association between the ITGAV rs10174098A/G SNP and knee OA.

Several recent studies have identified $F N-1$ mutations and polymorphisms that affect host susceptibility to a variety of diseases including calcium oxalate stone disease [21], schizophrenia [22], lung cancer [23], and fibrosing alveolitis in systemic sclerosis [24]. However, no previous studies have reported on an association between $F N-1$ polymorphisms and knee OA. The current study has, for the first time, revealed that the $F N-1$ intronic polymorphism rs940739A/T is associated with knee OA. SNPs in introns are known to influence the regulation of transcription, splicing, and other aspects of RNA processing or stability $[25,26]$. For instance, the intronic SNPs in FTO [27], COL1A1 [28], and BANK1 [29] affect primary transcript levels while the risk allele of the intronic SNP in the prothrombin gene may influence splicing efficiency [30]. However, it is currently unclear 
Table 6 Haplotype analysis of the three identified SNPs in FN-1 between OA cases and control subjects in both studies

\begin{tabular}{|c|c|c|c|c|c|c|}
\hline \multicolumn{3}{|l|}{ Haplotype } & \multicolumn{2}{|c|}{ Frequencies } & \multirow[t]{2}{*}{$p$} & \multirow[t]{2}{*}{ OR $(95 \% \mathrm{Cl})$} \\
\hline rs940739 & rs2304573 & rs11651 & Case & Control & & \\
\hline A & G & A & 0.581 & 0.597 & 0.386 & $0.94(0.82-1.08)$ \\
\hline $\mathrm{T}$ & G & G & 0.130 & 0.127 & 0.771 & $1.03(0.84-1.27)$ \\
\hline A & G & G & 0.095 & 0.099 & 0.729 & $0.96(0.76-1.21)$ \\
\hline A & A & G & 0.066 & 0.101 & $<0.001$ & $0.63(0.49-0.81)$ \\
\hline $\mathrm{T}$ & G & A & 0.047 & 0.024 & $<0.001$ & $2.03(1.35-3.06)$ \\
\hline A & A & A & 0.031 & 0.022 & 0.087 & $1.47(0.94-2.30)$ \\
\hline $\mathrm{T}$ & G & G & 0.027 & 0.021 & 0.289 & $1.28(0.81-2.03)$ \\
\hline $\mathrm{T}$ & A & A & 0.022 & 0.010 & 0.013 & $2.12(1.16-3.89)$ \\
\hline
\end{tabular}

whether the intronic SNP identified as being associated with knee OA in the current study performs a functional role by exerting a direct effect on $F N-1$ expression or whether it is in linkage disequilibrium with another functional SNP.

The role of FN and FN-fs in the development of knee $\mathrm{OA}$ is well recognized and supported by a number of studies. FN-fs, the central cell-, NH2-terminal heparin-, and $\mathrm{NH} 2$-terminal gelatin-binding fragments of FN have been shown to stimulate cartilage chondrolysis by inhibiting anabolic activity while increasing production of matrix metalloproteinases [31]. Importantly, FN-1 expression appears to be differentially regulated in monolayer cultured chondrocytes from OA and normal donors [32].

When we analyzed the association of SNP expression with the radiological grade of knee OA, a significant relationship was seen in patients with $\mathrm{KL}$ grade 4 knee OA with genotypes rs6725958C/A and rs940739A/T, indicating that these $F N-1$ polymorphisms are associated with advanced knee $\mathrm{OA}$ in the current Han Chinese population. The reasons for these associations are not clear. Genetic risk factors can influence the risk of development and progression of knee $\mathrm{OA}$ at various stages during the course of the disease. Because $F N-1$ polymorphisms could contribute to the risk of OA at different phases or throughout the disease process, further functional studies on such polymorphisms are required.

Haplotype analysis demonstrated an association between $F N-1$ and knee OA. Our data revealed that patients carrying TGA or TAA haplotypes had a higher risk of developing knee OA than those without, suggesting that multiple variants in $F N-1$ affect the risk. The $F N-1$ haplotype has previously been shown to have a significant influence on whether a fetus is at risk of being small-for-gestational-age [33], indicating that haplotype status could be important in tissue homeostasis.

Fibronectin and Fn-fs interact with chondrocytes and other joint tissue cells through integrins by which they can regulate cell function through a variety of intracellular signal cascades $[5,34,35]$. Although the $\alpha 5 \beta 1$ integrin is the major fibronectin receptor expressed by chondrocytes
[7], $\alpha \mathrm{V}$ is also abundantly expressed by articular chondrocytes; however, its biological significance in cartilage has been less well studied. ITGAV polymorphisms are associated with a number of conditions including rheumatoid arthritis [36], chronic hepatitis B virus infection [37], and primary biliary cirrhosis [38]. In the current study, the ITGAV SNP rs10174098A/G was only associated with knee OA when both study data were combined. Thus it is not entirely clear whether this weaker association with $\mathrm{OA}$ is genuine. Further independent studies need to be undertaken to clarify the situation.

\section{Conclusion}

The present study suggests that there is a significant association with the $F N-1$ polymorphism rs940739A/T and susceptibility to knee OA in a Chinese Han population. Such polymorphisms may explain why some individuals are at a higher risk for knee OA. Further studies on other larger populations combined with in vitro functional analyses are now crucial to elucidate the effects of the polymorphism on knee OA pathogenesis and susceptibility.

\section{Additional file}

Additional file 1: Table S1. Estimation of statistical power for the present study. Table S2. Genotype distributions and allele frequencies for the FN gene polymorphisms in male OA patients and healthy control groups. Table S3. Genotype distributions and allele frequencies for the FN gene polymorphisms in female OA patients and healthy control groups. Table S4. Genotype distributions and allele frequencies of the ITGAV gene by gender. Table S5. Analyses of the association of 10 SNPs in FN and ITGAV gene with OA (dominant model). Table S6. Analyses of the association of 10 SNPs in FN and ITGAV gene with OA (recessive model). Table S7. Joint effects of FN rs940739 and obesity among 928 cases of OA and 693 control subjects.

Competing interests

The authors declare that they have no competing interests.

\section{Authors' contributions}

HYY conceived, designed, and performed the experiments, analyzed the data, and wrote the paper. SLS conceived and designed the experiments, analyzed the data, and contributed reagents/materials/analysis tools. HSL conceived, 
designed and performed the experiments, contributed reagents/materials/ analysis tools, and wrote the paper. CHL conceived, designed and performed the experiments, contributed reagents/materials/analysis tools, and wrote the paper. YJP performed the experiments, and analyzed the data. CCW performed the experiments, and analyzed the data. DMS wrote the paper. All authors critically revised the manuscript and approved the final version.

\section{Acknowledgements}

This study was supported by grants from the National Science Council, National Defense Medical Center and Tri-Service General Hospital, Taiwan (S.L.S.: NSC99-2314-B-016-001; H.S.L.: TSGH-C102-068, MAB-102-57, NSC1002320-B-016-006; C.H.L.: NSC101-2314-B -038-004, NSC100-2314-B-038-04).

\section{Author details}

${ }^{1}$ School of Public Health, National Defense Medical Center, Taipei, Taiwan. ${ }^{2}$ Department of Pathology, Tri-Service General Hospital, National Defense Medical Center, Taipei, Taiwan. ${ }^{3}$ Department of Orthopedics, Tri-Service General Hospital and National Defense Medical Center, Taipei, Taiwan. ${ }^{4}$ Graduate Institute of Medical Sciences, National Defense Medical Center, Taipei, Taiwan. ${ }^{5}$ Centre for Molecular Medicine, MRC IGMM, University of Edinburgh, Edinburgh, UK. ' Department of Orthopedics, School of Medicine, College of Medicine, Taipei Medical University and Hospital, No.250, Wuxing St., Xinyi Dist, Taipei, Taiwan.

Received: 10 October 2013 Accepted: 19 May 2014

Published: 23 May 2014

\section{References}

1. Litwic A, Edwards MH, Dennison EM, Cooper C: Epidemiology and burden of osteoarthritis. Br Med Bull 2013, 105:185-199.

2. Neogi T, Zhang Y: Epidemiology of osteoarthritis. Rheum Dis Clin North Am 2013, 39:1-19

3. Kuettner KE, Cole AA: Cartilage degeneration in different human joints. Osteoarthritis Cartilage 2005, 13:93-103.

4. Yasuda T: Cartilage destruction by matrix degradation products. Mod Rheumatol 2006, 16:197-205.

5. Sofat N: Analysing the role of endogenous matrix molecules in the development of osteoarthritis. Int J Exp Pathol 2009, 90:463-479.

6. Werb Z, Tremble PM, Behrendtsen O, Crowley E, Damsky CH: Signal transduction through the fibronectin receptor induces collagenase and stromelysin gene expression. J Cell Biol 1989, 109:877-889.

7. Woods VL Jr, Schreck PJ, Gesink DS, Pacheco HO, Amiel D, Akeson WH, Lotz M: Integrin expression by human articular chondrocytes. Arthritis Rheum 1994, 37:537-544.

8. Salter DM, Hughes DE, Simpson R, Gardner DL: Integrin expression by human articular chondrocytes. Br J Rheumatol 1992, 31:231-234.

9. Rencic A, Gehris AL, Lewis SD, Hume EL, Bennett VD: Splicing patterns of fibronectin mRNA from normal and osteoarthritic human articular cartilage. Osteoarthritis Cartilage 1995, 3:187-196.

10. White ES, Baralle FE, Muro AF: New insights into form and function of fibronectin splice variants. J Pathol 2008, 216:1-14.

11. Homandberg GA, Suppl 391: Cartilage damage by matrix degradation products: fibronectin fragments. Clin Orthop Relat Res 2001 Oct, (Supp391):100-107.

12. Calderwood DA: Integrin activation. I Cell Sci 2004, 117:657-666,

13. Sims MA, Field SD, Barnes MR, Shaikh N, Ellington K, Murphy KE, Spurr N, Campbell DA: Cloning and characterisation of ITGAV, the genomic sequence for human cell adhesion protein (vitronectin) receptor alpha subunit, CD51. Cytogenet Cell Genet 2000, 89:268-271.

14. Iliopoulos D, Malizos KN, Oikonomou P, Tsezou A: Integrative microRNA and proteomic approaches identify novel osteoarthritis genes and their collaborative metabolic and inflammatory networks. PLoS One 2008, 3:e3740.

15. arCOGEN Consortium, arCOGEN Collaborators, Zeggini E, Panoutsopoulou K, Southam L, Rayner NW, Day-Williams AG, Lopes MC, Boraska V, Esko T, Evangelou E, Hoffman A, Houwing-Duistermaat JJ, Ingvarsson T, Jonsdottir I, Jonnson H, Kerkhof HJ, Kloppenburg M, Bos SD, Mangino M, Metrustry S, Slagboom PE, Thorleifsson G, Raine EV, Ratnayake M, Ricketts M, Beazley C, Blackburn H, Bumpstead S, Elliott KS, et al: Identification of new susceptibility loci for osteoarthritis (arCOGEN): a genome-wide association study. Lancet 2012, 380:815-823.
16. Reynard LN, Loughlin J: Genetics and epigenetics of osteoarthritis. Maturitas 2012, 71:200-204

17. Valdes AM, Spector TD: The genetic epidemiology of osteoarthritis. Curr Opin Rheumatol 2010, 22:139-143.

18. Pulai Jl, Del Carlo M Jr, Loeser RF: The alpha5beta1 integrin provides matrix survival signals for normal and osteoarthritic human articular chondrocytes in vitro. Arthritis Rheum 2002, 46:1528-1535.

19. Kim SJ, Kim EJ, Kim YH, Hahn SB, Lee JW: The modulation of integrin expression by the extracellular matrix in articular chondrocytes. Yonsei Med J 2003, 44:493-501.

20. Barrett JC, Fry B, Maller J, Daly MJ: Haploview: analysis and visualization of LD and haplotype maps. Bioinformatics 2005, 21:263-265.

21. Onaran M, Yilmaz A, Sen I, Ergun MA, Camtosun A, Kupeli B, Menevse S, Bozkirli I: A Hindlll polymorphism of fibronectin gene is associated with nephrolithiasis. Urology 2009, 74:1004-1007.

22. Nakata K, Ujike H, Sakai A, Takaki M, Imamura T, Tanaka Y, Kuroda S: Association study between the fibronectin gene and schizophrenia. Am J Med Genet B Neuropsychiatr Genet 2003, 116B:41-44.

23. Siemianowicz K, Gminski J, Francuz T, Syzdol M, Polanska D, Machalski M, Brulinski K, Magiera-Molendowska H: Fibronectin gene polymorphism in patients with lung cancer. Oncol Rep 2001, 8:1289-1292.

24. Avila JJ, Lympany PA, Pantelidis P, Welsh KI, Black CM, Du Bois RM: Fibronectin gene polymorphisms associated with fibrosing alveolitis in systemic sclerosis. Am J Respir Cell Mol Biol 1999, 20:106-112.

25. Birney E, Lieb JD, Furey TS, Crawford GE, lyer VR: Allele-specific and heritable chromatin signatures in humans. Hum Mol Genet 2010, 19:R204-R209.

26. Cheung VG, Spielman RS: Genetics of human gene expression: mapping DNA variants that influence gene expression. Nat Rev Genet 2009, 10:595-604.

27. Berulava T, Horsthemke B: The obesity-associated SNPs in intron 1 of the FTO gene affect primary transcript levels. Eur J Hum Genet 2010, 18:1054-1056

28. Mann V, Hobson EE, Li B, Stewart TL, Grant SF, Robins SP, Aspden RM, Ralston SH: A COL1A1 Sp1 binding site polymorphism predisposes to osteoporotic fracture by affecting bone density and quality. J Clin Invest 2001, 107:899-907.

29. Kozyrev SV, Abelson AK, Wojcik J, Zaghlool A, Linga Reddy MV, Sanchez E, Gunnarsson I, Svenungsson E, Sturfelt G, Jönsen A, Truedsson L, Pons-Estel BA, Witte T, D'Alfonso S, Barizzone N, Danieli MG, Gutierrez C, Suarez A, Junker P, Laustrup H, González-Escribano MF, Martin J, Abderrahim H, Alarcón-Riquelme ME: Functional variants in the B-cell gene BANK1 are associated with systemic lupus erythematosus. Nat Genet 2008, 40:211-216.

30. Von Ahsen N, Oellerich M: The intronic prothrombin 19911A > G polymorphism influences splicing efficiency and modulates effects of the $20210 \mathrm{G}>$ A polymorphism on mRNA amount and expression in a stable reporter gene assay system. Blood 2004, 103:586-593.

31. Homandberg GA, Costa V, Wen C: Fibronectin fragments active in chondrocytic chondrolysis can be chemically cross-linked to the alpha5 integrin receptor subunit. Osteoarthritis Cartilage 2002, 10:938-949.

32. Dehne T, Karlsson C, Ringe J, Sittinger M, Lindahl A: Chondrogenic differentiation potential of osteoarthritic chondrocytes and their possible use in matrix-associated autologous chondrocyte transplantation. Arthritis Res Ther 2009, 11:R133.

33. Edwards DR, Romero R, Kusanovic JP, Hassan SS, Mazaki-Tovi S, Vaisbuch E, Kim CJ, Erez O, Chaiworapongsa T, Pearce BD, Bartlett J, Friel LA, Salisbury BA, Anant MK, Vovis GF, Lee MS, Gomez R, Behnke E, Oyarzun E, Tromp G, Menon R, Williams SM: Polymorphisms in maternal and fetal genes encoding for proteins involved in extracellular matrix metabolism alter the risk for small-for-gestational-age. J Matern Fetal Neonatal Med 2011, 24:362-380

34. Kostopoulou F, Gkretsi V, Malizos KN, lliopoulos D, Oikonomou P, Poultsides $L$, Tsezou A: Central role of SREBP-2 in the pathogenesis of osteoarthritis. PLoS One 2012, 7:e35753.

35. Guilak F: Biomechanical factors in osteoarthritis. Best Pract Res Clin Rheumatol 2011, 25:815-823.

36. Hollis-Moffatt JE, Rowley KA, Phipps-Green AJ, Merriman ME, Dalbeth N, Gow P, Harrison AA, Highton J, Jones PB, Stamp LK, Harrison P, Wordsworth BP, Merriman TR: The ITGAV rs3738919 variant and susceptibility to rheumatoid arthritis in four Caucasian sample sets. Arthritis Res Ther 2009, 11:R152. 
37. Lee SK, Kim MH, Cheong JY, Cho SW, Yang SJ, Kwack K: Integrin alpha V polymorphisms and haplotypes in a Korean population are associated with susceptibility to chronic hepatitis and hepatocellular carcinoma. Liver Int 2009, 29:187-195.

38. Inamine T, Nakamura M, Kawauchi A, Shirakawa Y, Hashiguchi H, Aiba Y, Taketomi A, Shirabe K, Nakamuta M, Hayashi S, Saoshiro T, Komori A Yatsuhashi H, Kondo S, Omagari K, Maehara Y, Ishibashi H, Tsukamoto K, PBC Study Group in NHOSLJ: A polymorphism in the integrin alphaV subunit gene affects the progression of primary biliary cirrhosis in Japanese patients. J Gastroenterol 2011, 46:676-686.

doi:10.1186/1471-2474-15-173

Cite this article as: Yang et al:: An intron polymorphism of the

fibronectin gene is associated with end-stage knee osteoarthritis in a Han Chinese population: two independent case-control studies. BMC

Musculoskeletal Disorders 2014 15:173.

\section{Submit your next manuscript to BioMed Central and take full advantage of:}

- Convenient online submission

- Thorough peer review

- No space constraints or color figure charges

- Immediate publication on acceptance

- Inclusion in PubMed, CAS, Scopus and Google Scholar

- Research which is freely available for redistribution 